\title{
A Study on High Frequency-Plasma Enhanced Chemical Vapor Deposition Silicon Nitride Films for Crystalline Silicon Solar Cells
}

\author{
Zhen-Hua Li, Si-Cheol Roh, Dong-Yeol Ryu, Jeong-Ho Choi, and Hwa-Il Seo ${ }^{\dagger}$ \\ Department of Electrical and Electronic Engineering, Korea University of Technology and Education, Cheonan 330-708, Korea \\ Yeong-Cheol Kim \\ Department of Materials Engineering, Korea University of Technology and Education, Cheonan 330-708, Korea
}

Received March 25, 2011; Revised June 29, 2011; Accepted June 29, 2011

SiNx:H films have been widely used for anti-reflection coatings and passivation for crystalline silicon solar cells. In this study, SiNx:H films were deposited using high frequency (13.56 MHz) direct plasma enhanced chemical vapor deposition, and the optical and passivation properties were investigated. The radio frequency power, the spacing between the showerhead and wafer, the $\mathrm{NH}_{3} / \mathrm{SiH}_{4}$ ratio, the total gas flow, and the $\mathrm{N}_{2}$ gas flow were changed over certain ranges for the film deposition. The thickness uniformity, the refractive index, and the minority carrier lifetime were then measured in order to study the properties of the film. The optimal deposition conditions for application to crystalline Si solar cells are determined from the results of this study.

Keywords: High frequency-plasma enhanced chemical vapor deposition, Silicon nitride, Refractive index, Thickness uniformity, Minority carrier lifetime

\section{INTRODUCTION}

The solar cells industry has been developing quickly and steadily, with a strong momentum in the entire photovoltaic market. There are different methods used to achieve high efficiency solar cells; anti-reflection coating technology is one of them.

Plasma enhanced chemical vapor deposition (PECVD) SiNx:H films which act as anti-reflection coatings have recently been widely used in the industrial fabrication of crystalline silicon solar cells. The SiNx:H films not only reduce optical losses but also provide a reasonable degree of surface passivation [1]. Regarding the optical properties, the refractive index is often chosen to be about 2.0 [2] and the thickness varies from $70 \sim 80 \mathrm{~nm}$. These

${ }^{\dagger}$ Author to whom all correspondence should be addressed: E-mail: hiseo@kut.ac.kr

Copyright $@ 2011$ KIEEME. All rights reserved.

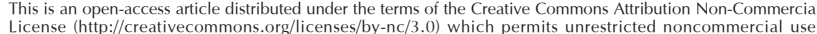
License (inte:/)
distribution, and reproduction in films passivate the surface dangling bonds. During firing, a part of the hydrogen in the SiNx:H films is released to the air and the other part diffuses into the SiNx:H/Si interface and combines with the defects, such as the dangling bonds, so that the defects become inactive.

There are two different PECVD methods: direct PECVD and remote PECVD. In direct PECVD reactors, all of the processing gases are excited by an electromagnetic field; the samples are located within the plasma. The electromagnetic field has a frequency of either $13.56 \mathrm{MHz}$ ('high frequency') or in the 10 500 $\mathrm{KHz}$ range ('low frequency'). In remote PECVD reactors, the excitation of the plasma is spatially separated from the samples and one type of these different plasma excitations, such as microwaves, hollow cathode, arc jet, etc. is used [1].

There are not many studies regarding high frequency direct PECVD (HF-PECVD) SiNx:H films. Regarding the use of different PECVD systems, there has been no consensus on deposition conditions so far. Also In addition, different parameters play different roles in the PECVD processes [3]. 


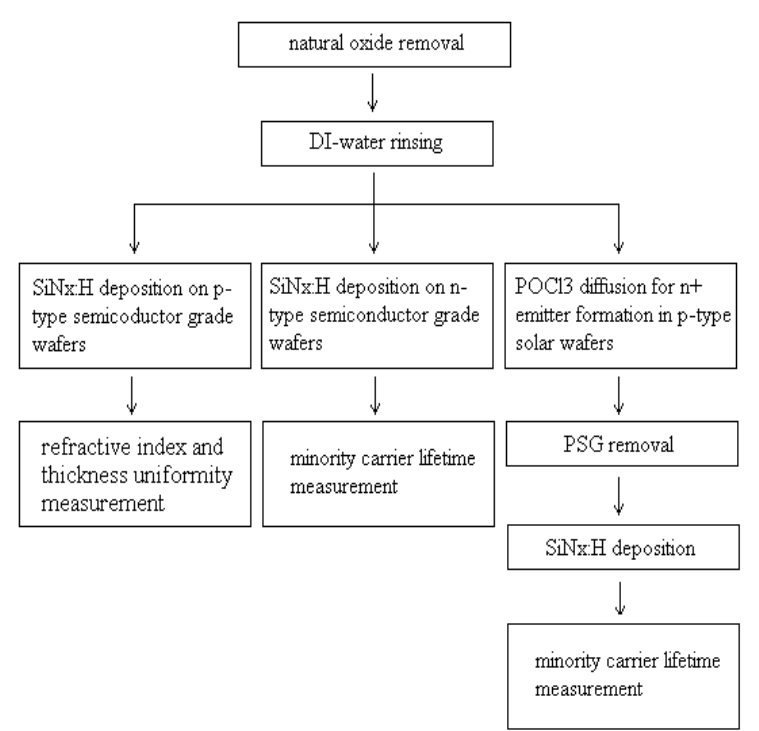

Fig. 1. The process sequences used in this study. PSG: phosphorus glass layer.

In this study SiNx:H films were deposited by HF-PECVD, using $\mathrm{NH}_{3}$ and $\mathrm{SiH}_{4}$ as the reaction gases in the $\mathrm{N}_{2}$ ambient gas. In order to obtain the optimal deposition conditions, some parameters need to be taken into account, such as deposition temperature, pressure, radio frequency $(\mathrm{RF})$ power, the spacing between the showerhead and wafer, the $\mathrm{NH}_{3} / \mathrm{SiH}_{4}$ ratio, total reaction gas flow, and $\mathrm{N}_{2}$ gas flow. In this study, the deposition process was fixed at $400^{\circ} \mathrm{C}$ and 1 Torr, which has been discussed in former works [3]. The remaining parameters were varied over certain ranges. The optical and passivation properties of the films for crystalline solar cells were evaluated by investigating the refractive index, thickness uniformity and minority carrier lifetime.

\section{EXPERIMENTS}

The basic process sequences are shown in Fig. 1. The experiments consisted of two groups for the study of the optical properties and the passivation properties, respectively. For both groups, the deposition temperature was fixed at $400^{\circ} \mathrm{C}$ and the pressure was fixed at 1 Torr. Before deposition, all of the wafers were treated with an HF solution to remove the natural oxides and rinsed using deionized (DI)-water. A high frequency PECVD system (P-5000; Applied Materials, Santa Clara, CA, USA) was then used for the deposition process.

In the first group, for the optical properties study, 4 inch semiconductor grade polished p-type $\mathrm{CZ}<100>$ crystalline $\mathrm{Si}$ wafers were used in the deposition process. The RF power, the spacing between the showerhead and wafer, the total gas flow, and the $\mathrm{N}_{2}$ gas flow were varied over certain ranges. Finally the thickness was measured at five different points on the films by thickness measurement equipment in order to obtain the thickness uniformity values. The refractive index was measured at about a 630 $n m$ wavelength using an ellipsometry.

The second group, used to study the passivation properties, both semiconductor grade $\mathrm{n}$-type $\mathrm{CZ}<100>\mathrm{Si}$ wafers and solar grade p-type $\mathrm{CZ}<100>\mathrm{Si}$ wafers were used in the deposition process. In the case of the solar grade p-type wafers, before the deposition of the SiNx:H films, an $\mathrm{n}+$ emitter was formed by $\mathrm{POCl}_{3}$ diffusion leading to a $60 \Omega / \mathrm{sq}$ emitter sheet resistance. After the deposition, firing was executed at $850^{\circ} \mathrm{C}$ for 30 seconds. Finally
$\mathrm{NH} 3=160 \mathrm{sccm}$
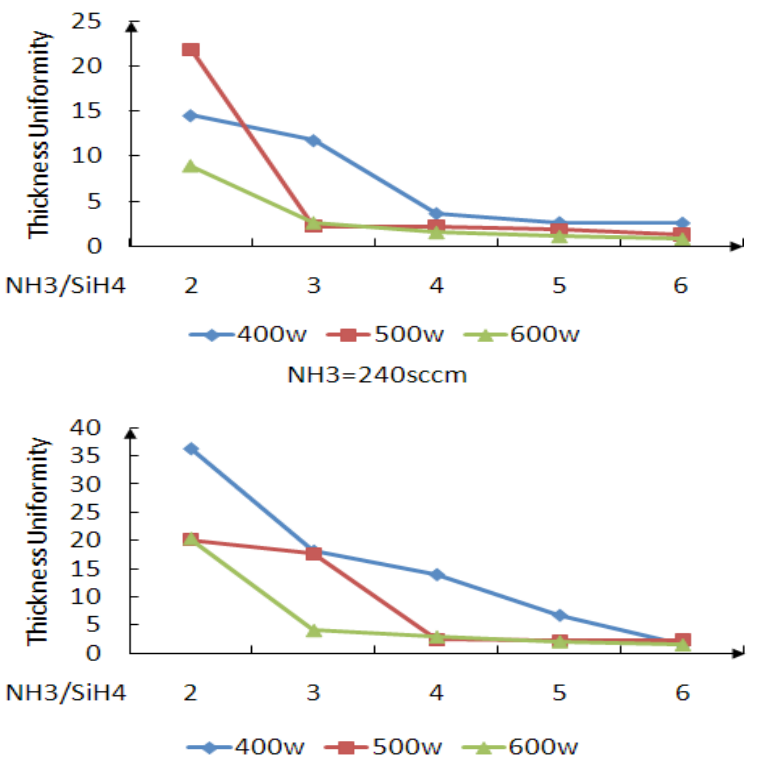

$\mathrm{NH} 3=320 \mathrm{sccm}$

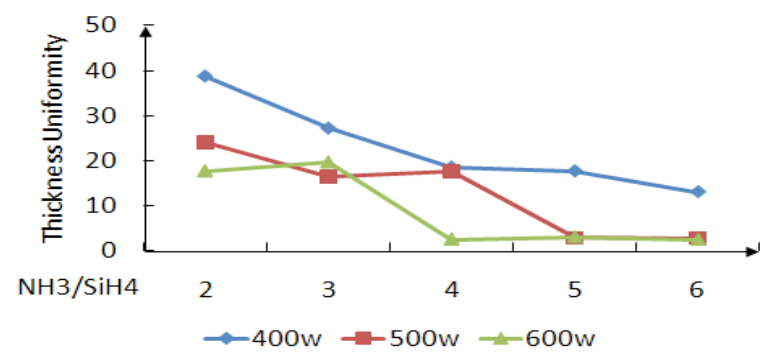

Fig. 2. (a) The thickness uniformity as a function of the $\mathrm{NH}_{3} / \mathrm{SiH}_{4}$ ratio at 400,500 , and $600 \mathrm{~W}$.

the minority carrier lifetime was obtained through the microwave-detected photoconductance decay $(\mu-P C D)$ method [4].

\section{RESULTS AND DISCUSSION}

\subsection{Thickness uniformity and the refractive index}

For the experiments, the $\mathrm{NH}_{3}$ gas flow was set to either 160, 240 and $320 \mathrm{sccm}$. The $\mathrm{NH}_{3} / \mathrm{SiH}_{4}$ ratio varied over the range of 2, $3,4,5$ and 6 . The $\mathrm{N}_{2}$ gas flow was fixed at $240 \mathrm{sccm}$. The spacing between the showerhead and wafer was fixed at 320 mil. The RF power was varied over 400,500 and $600 \mathrm{~W}$; the changes in the thickness uniformity and refractive index of the films are shown in Figs. 2(a) and (b), respectively.

The numerical values of the thickness uniformity show the quality of the thickness homogeneity in the SiNx:H films. The higher numerical values mean a bad homogeneity and the low ones represent a good homogeneity. As seen in Fig. 2(a), all three cases have the same tendency in that the thickness uniformity improves as the RF power increases. It also improves as the $\mathrm{NH}_{3} /$ $\mathrm{SiH}_{4}$ ratio increases. So, when the RF power equals $600 \mathrm{~W}$ and the $\mathrm{NH}_{3} / \mathrm{SiH}_{4}$ ratio is greater than 4 , a good thickness homogeneity of SiNx:H films will be obtained.

In the same way, shown in Fig. 2(b), all three cases have the same tendency in that the refractive index obviously decreases as the $\mathrm{NH}_{3} / \mathrm{SiH}_{4}$ ratio increases. But it only slightly decreases as the RF power increases. Notably, when the $\mathrm{NH}_{3} / \mathrm{SiH}_{4}$ ratio equaled 2, 

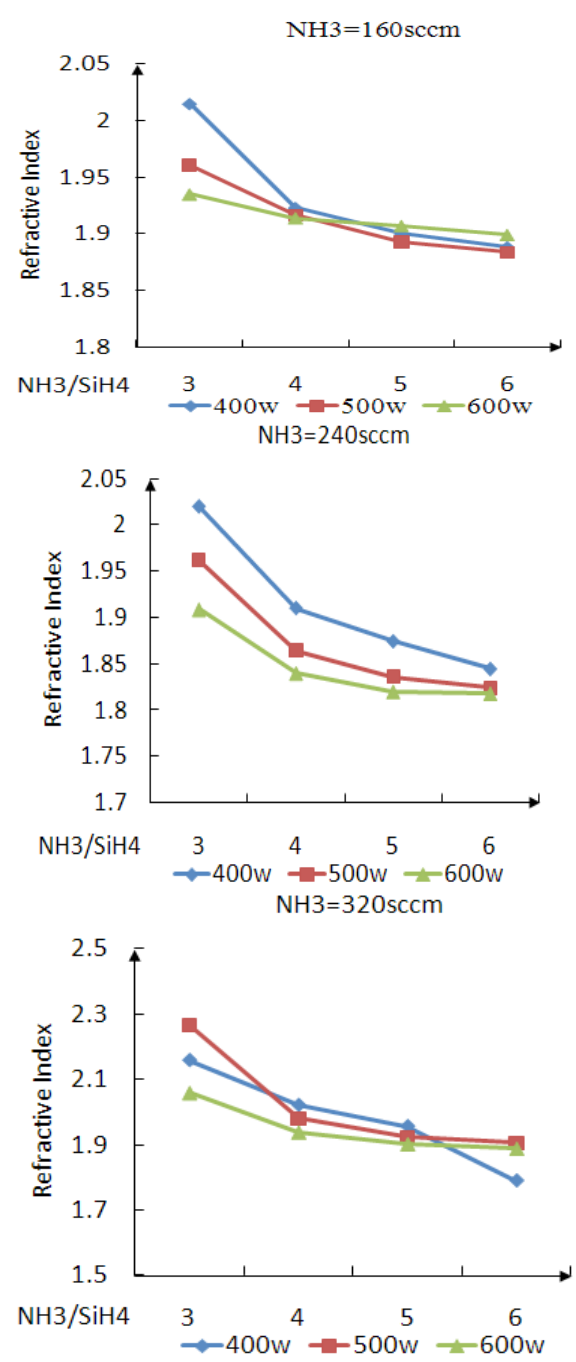

Fig. 2. (b) The refractive index as a function of the $\mathrm{NH}_{3} / \mathrm{SiH}_{4}$ ratio at 400,500 and $600 \mathrm{~W}$.

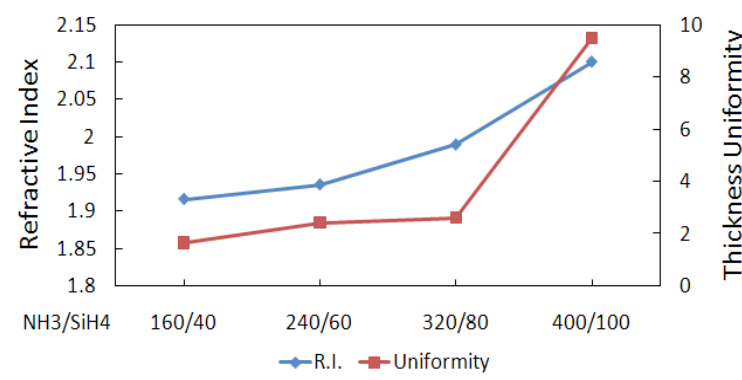

Fig. 3. The variation of the refractive index and thickness uniformity as both the $\mathrm{NH}_{3}$ and $\mathrm{SiH}_{4}$ gas flow increased proportionally.

the thickness homogeneity was so terrible that the refractive index could not be measured. The refractive index decreases as the $\mathrm{NH}_{3} /$ $\mathrm{SiH}_{4}$ ratio increases, due to the fact that the films become less $\mathrm{Si}-$ rich as the amount of $\mathrm{SiH}_{4}$ decreases leading to N-rich films [5,6].

With the thickness uniformity taken into account, the optimal $\mathrm{RF}$ power was determined to be $600 \mathrm{~W}$ and the $\mathrm{NH}_{3} / \mathrm{SiH}_{4}$ ratio as 4 , which has the closest refractive index to 2.0 among the three cases. Therefore, in the following experiments, the RF power was fixed at $600 \mathrm{~W}$ and the $\mathrm{NH}_{3} / \mathrm{SiH}_{4}$ ratio was fixed at 4 .

The $\mathrm{NH}_{3} / \mathrm{SiH}_{4}$ ratio was fixed to 4 and the $\mathrm{NH}_{3} / \mathrm{SiH}_{4}$ gas flow increased proportionally, at 160/40, 240/60, 320/80 and 400/100

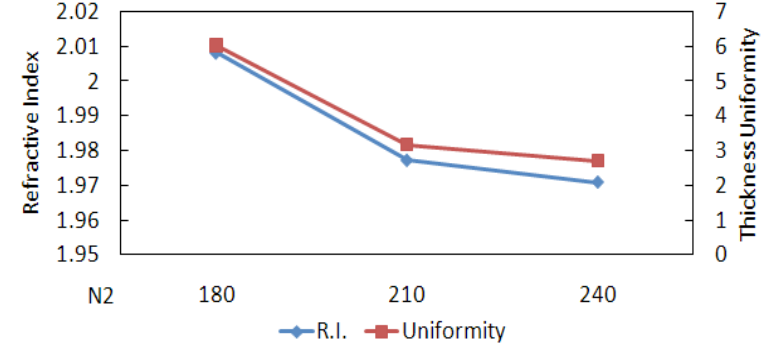

Fig. 4. The variation of the refractive index and thickness uniformity as the $\mathrm{N}_{2}$ gas flow increased over the range of 180, 210 and $240 \mathrm{sccm}$.

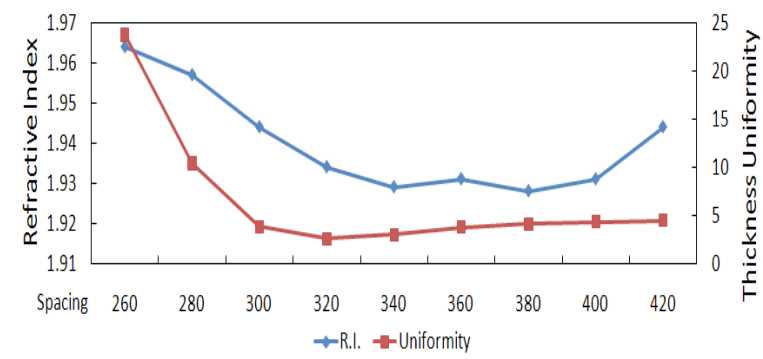

Fig. 5. The variation of the refractive index and thickness uniformity as the spacing between the showerhead and wafer increased over the range of 260, 280, 300, 320, 340, 360, 380, 400 and 420 mil.

sccm; the resulting variations of the refractive index and thickness uniformity are shown in Fig. 3 . The $\mathrm{N}_{2}$ gas flow was fixed at $240 \mathrm{sccm}$. Obviously, as the gas flow increased, both the refractive index and the numerical values of the thickness uniformity increased. The increment in the refractive index is considered to be due to the fact that the high gas flow causes the films to become more Si-rich [7]. In addition, the increment of the $\mathrm{NH}_{3} / \mathrm{SiH}_{4}$ gas flow results in a bad thickness homogeneity. Notably, when the $\mathrm{NH}_{3} / \mathrm{SiH}_{4}$ gas flow equaled $400 / 100 \mathrm{sccm}$, the thickness homogeneity was the worst one recorded for the four films. However, when the $\mathrm{NH}_{3} / \mathrm{SiH}_{4}$ gas flow equaled $320 / 80 \mathrm{sccm}$, the refractive index was closest to 2.0 and the thickness homogeneity was also good. So the optimal $\mathrm{NH}_{3} / \mathrm{SiH}_{4}$ gas flow was determined to be $320 / 80 \mathrm{sccm}$.

The $\mathrm{NH}_{3} / \mathrm{SiH}_{4}$ gas flow was fixed to $320 \mathrm{sccm}$ and $80 \mathrm{sccm}$, respectively, and the $\mathrm{N}_{2}$ gas flow was addressed in the next experiments. As seen in Fig. 4, the $\mathrm{N}_{2}$ gas flow was varied over the range of 180,210 and $240 \mathrm{sccm}$.

As $\mathrm{N}_{2}$ gas flow increased, the refractive index decreased, but the thickness homogeneity was improved. The decrease of refractive index is due to the increment of the $\mathrm{N}_{2}$ gas flow resulting in making the films more $\mathrm{N}$-rich. Therefore, in order to maintain a good thickness homogeneity, $240 \mathrm{sccm}$ was chosen as the optimal $\mathrm{N}_{2}$ gas flow.

Figure 5 shows the effects of the showerhead and wafer spacing on the refractive index and thickness uniformity. The RF power, $\mathrm{NH}_{3} / \mathrm{SiH}_{4}$ gas ratio and $\mathrm{N}_{2}$ gas flow were se to $600 \mathrm{~W}$, $320 / 80,240 \mathrm{sccm}$, respectively. As the spacing between the showerhead and wafer increased, the refractive index changes over a certain range, but the thickness homogeneity becomes better. Consequently, with the thickness uniformity taken into account first, 320 mil was chosen for the spacing between the showerhead and wafer.

\subsection{Minority carrier lifetime}

In the previous sub-section, some optimal parameters were determined. The RF power $=600 \mathrm{~W}, \mathrm{NH}_{3}$ gas flow $=320 \mathrm{sccm}, \mathrm{N}_{2}$ 


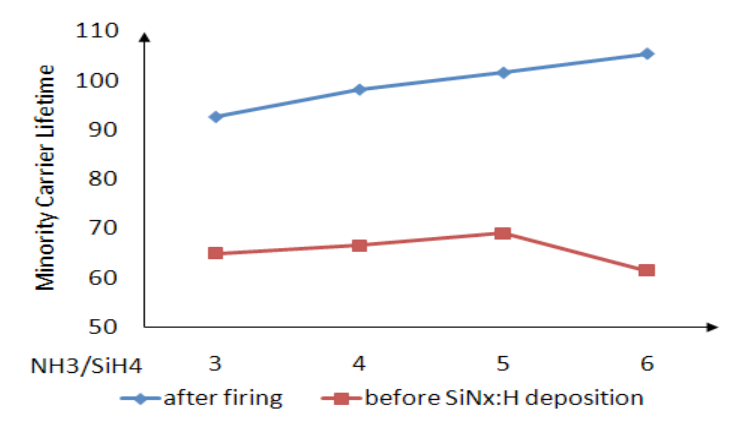

Fig. 6. The minority carrier lifetime as a function of the $\mathrm{NH}_{3} / \mathrm{SiH}_{4}$ ratio on the n-type semiconductor grade wafers.

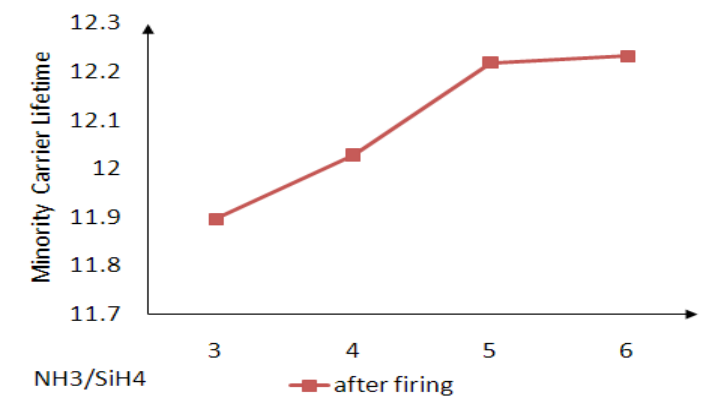

Fig. 7. The minority carrier lifetime as a function of the $\mathrm{NH}_{3} / \mathrm{SiH}_{4}$ ratio on the p-type solar grade wafers.

gas flow $=240 \mathrm{sccm}$, and the spacing between showerhead and wafer $=320$ mil were fixed.

In order to study the passivation properties of the films, two kinds of experiments were performed. One was that the SiNx:H films were deposited on n-type semiconductor grade wafers and fired at $850^{\circ} \mathrm{C}$. The resulting variations in the minority carrier lifetime are shown in Fig. 6.

The other experiment had the SiNx:H films deposited after a $\mathrm{POCl}_{3}$ diffusion, which led to a $60 \Omega /$ sq emitter sheet resistance. The firing was executed at $850^{\circ} \mathrm{C}$ in the same manner as the first passivation experiment. The resulting variations in the minority carrier lifetime are shown in Fig. 7.

Both of the experiments showed the same tendency regarding the minority carrier lifetime. As the $\mathrm{NH}_{3} / \mathrm{SiH}_{4}$ ratio increased, minority carrier lifetime improved. The $\mathrm{NH}_{3} / \mathrm{SiH}_{4}$ ratio plays a very important role in influencing the refractive index and passivation. This is because the different $\mathrm{NH}_{3} / \mathrm{SiH}_{4}$ ratios cause different chemical compositions in the SiNx:H films. A high $\mathrm{NH}_{3} /$ $\mathrm{SiH}_{4}$ ratio leads to a more N-rich SiNx:H film. Contrarily, a low $\mathrm{NH}_{3} / \mathrm{SiH}_{4}$ ratio leads to a more Si-rich SiNx:H film. In addition, Fig. 6 shows that the minority carrier lifetime increases greatly after firing, compared to that before the SiNx:H deposition.

The results shown in Figs. 6 and 7 can be explained by the following: During the firing process, the Si-H and N-H bonds in the films are broken due to the high temperature. A part of hydrogen becomes the molecular form $\mathrm{H}_{2}$, which is released into the air. The other part of the hydrogen still keeps its atomic form and diffuses into the SiNx:H/Si interface, passivating the defects, such as dangling bonds. In the Si-rich films, there are a great many $\mathrm{Si}-\mathrm{H}$ bonds, which are easier to break in the high temperature process than $\mathrm{N}-\mathrm{H}$ bonds. Because the films become less dense, more hydrogen is released in the molecular form and less hydrogen diffuses into the SiNx:H/Si interface in the atomic form. Otherwise, in the N-rich films, there are a great many $\mathrm{N}-\mathrm{H}$

\begin{tabular}{lc}
\hline \multicolumn{1}{c}{ Parameters } & Conditions \\
\hline \hline Temperature $\left({ }^{\circ} \mathrm{C}\right)$ & 400 \\
Pressure (Torr) & 1 \\
RF power $(\mathrm{W})$ & 600 \\
Gas flow (sccm) & $\mathrm{NH} 3=320, \mathrm{SiH} 4=80, \mathrm{~N} 2=240$ \\
Spacing between & 320 \\
showerhead and wafer (mil) & \\
\hline
\end{tabular}

bonds, which are more difficult to break in the high temperature process compared to the $\mathrm{Si}-\mathrm{H}$ bonds. Meanwhile, because the films become denser, less hydrogen is released in the molecular form and more hydrogen diffuses into the substrates in the atomic form. So the N-rich films provide a better passivation than the Si-rich ones. In addition, after firing, the films with the high $\mathrm{NH}_{3} / \mathrm{SiH}_{4}$ ratio also provided high values for the minority carrier lifetime $[7,8]$.

\section{CONCLUSIONS}

In this study, SiNx:H films were deposited using high frequency (13.56 MHz) direct PECVD for application to crystalline Si solar cells, and the optical and passivation properties were investigated. The RF power, the spacing between the showerhead and wafer, the $\mathrm{NH}_{3} / \mathrm{SiH}_{4}$ ratio, the total gas flow, and the $\mathrm{N}_{2}$ gas flow were varied over certain ranges for the experiments. The thickness uniformity, refractive index and minority carrier lifetime were then measured in order to study the properties of the film.

A $\mathrm{NH}_{3} / \mathrm{SiH}_{4}$ ratio of 4 was determined to be the optimal $\mathrm{NH}_{3} /$ $\mathrm{SiH}_{4}$ ratio, because it can provide a relatively good passivation and good thickness homogeneity, obtaining a refractive index closest to 2.0 among the $\mathrm{NH}_{3} / \mathrm{SiH}_{4}$ ratios greater than 4 . The final optimal conditions are given in Table 1.

When the $\mathrm{NH}_{3} / \mathrm{SiH}_{4}$ ratio increased, better passivation effects were obtained. So for some cases that the passivation properties need to be taken into account first, an $\mathrm{NH}_{3} / \mathrm{SiH}_{4}$ ratio greater than 4 can be selected for the film deposition.

\section{REFERENCES}

[1] A. G. Aberle, Sol. Energy Mater. Sol. Cells 65, 239 (2001) [DOI: 10.1016/s0927-0248(00)00099-4].

[2] R. Jayakrishnan and P. Suratkar, Photovoltaics Int. Edition 6, 83 (2009).

[3] H. F. W. Dekkers, S. De Wolf, G. Agostinelli, F. Duerinckx, and G. Beaucarne, Sol. Energy Mater. Sol. Cells 90, 3244 (2006) [DOI: 10.1016/j.solmat.2006.06.024].

[4] S. Rein, Lifetime Spectroscopy: A Method of Defect Characterization in Silicon for Photovoltaic Application, ed. S. Rein (Springer Berlin, Heidelberg, 2005) p. 59 [DOI: 10.1007/3-540-27922-9_3].

[5] A. El amrani, I. Menous, L. Mahiou, R. Tadjine, A. Touati, and A. Lefgoum, Renew. Energ. 33, 2289 (2008) [DOI: 10.1016/ j.renene.2007.12.015].

[6] M. Bose, D. K. Basa, and D. N. Bose, Mater. Lett. 48, 336 (2001) [DOI: 10.1016/s0167-577x(00)00323-2].

[7] J. F. Lelièvre, E. Fourmond, A. Kaminski, O. Palais, D. Ballutaud, and M. Lemiti, Sol. Energy Mater. Sol. Cells 93, 1281 (2009) [DOI: 10.1016/j.solmat.2009.01.023].

[8] C. Andres, C. Florence, T. Jason, M. Helmut, W. Saul, and R. Kristin, Conference Record of the 2006 IEEE 4th World Conference on Photovoltaic Energy Conversion (Waikoloa, HI 2006 May 7-12) p. 1148. [DOI: 10.1109/WCPEC.2006.279365. 